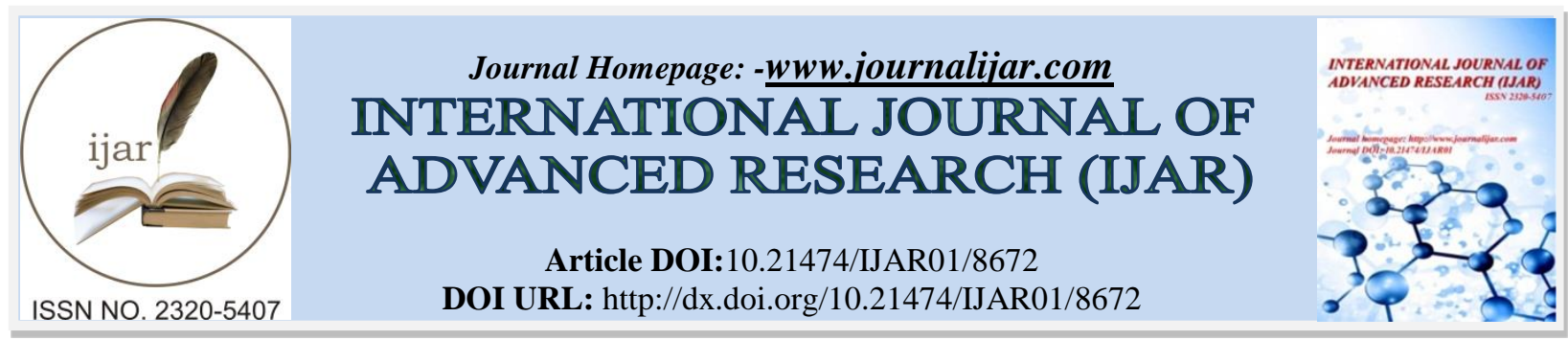

RESEARCH ARTICLE

\title{
OUR EXPERIENCE OF RHOMBOID EXCISION WITH LIMBERG FLAP RECONSTRUCTION IN PILONIDAL SINUS DISEASE.
}

Dr. Showket Majeed ${ }^{1}$ and Dr. Zahida Akhtar ${ }^{2}$.

1. Medical Officer Government Health Services Kashmir.

2. Asst. Professor Department Of General and Minimal Access Surgery, SKIMS, Medical College, Kashmir.

\section{Manuscript Info}

Manuscript History

Received: 12 January 2018

Final Accepted: 14 February 2019

Published: March 2019

Key words:-

Pilonidal sinus, Limberg flap, Rhomboid Excision.

\section{Abstract}

Background: Pilonidal sinus is a hair containing sinus at the cleft of buttocks. The treatment should have rapid cure that allows patients to return quickly to their normal activities, with minimum morbidity. Limberg flap reconstruction of pilonidal sinus is frequently performed at our centre.

Methods and Patients: This prospective study was conducted in the department of surgery rural centre of Kashmir from November 2013 to February 2015. A total number of 25 patients were treated with rhomboid excision with limberg flap reconstruction during this period. Parameters like postoperative complications, hospital stay, time offwork and recurrences were recorded. The patients were followed in the outpatient department for a period of six months.

Results: Of the 25 patients in our study 15 patients presented with a discharging sinus, 6 patients presented with pain, 2 with abscess and 2 with infection. In our study the operative time ranged from 50 minutes to 90 minutes. Drain was removed after 48-72 hours and patients were discharged the same day as the removal of drain. Sutures were removed on $12^{\text {th }}-15^{\text {th }}$ postoperative day. One patient in our study developed wound site infection, one patient had seroma, while as one patient had flap necrosis at the tip of the flap. Overall only one patient had a recurrence during the follow-up.

Conclusion: Rhomboid excision with limberg reconstruction flap procedure is a very effective procedure for pilonidal sinus disease. It is associated with a low recurrence, a shorter hospital stay, less complication rates and faster healing.

Copy Right, IJAR, 2019,. All rights reserved.

\section{Introduction:-}

Pilonidal sinus is a hair containing sinus at the cleft of buttocks. The disease is more commonly seen in young adults. In U.S the incidence of disease is approximately 26 per 100000 .The etiology of disease is not clearly known and is controversial. It is believed to result from the implantation of loose hair into the depth of natal cleft $(1,2)$. Risk factors which have been associated with the disease are excessive sweating due to friction or while sitting, poor personal hygiene, obesity, local trauma, narrowness of natal cleft, etc. $(3,4)$. Once the loose hair is implanted it leads to infection and abscess formation and later on to pilonidal sinus formation. There is a debate regarding an ideal 
procedure for the treatment of pilonidal sinus disease. The principles of PS treatment are total excision of the sinus tract, closure of the resultant defect and prevention of recurrence. A close relationship exists between success of surgical procedure and postoperative morbidity and recurrence. The different surgical methods for management of PS, including shaving [5], phenol application [6], unroofing and curettage [7], open treatment, repair with partial and primary suture [8], repair with a local flap [9-14], and repair with a local or distant faciocutaneous and musculocutaneous flap [15]. An ideal procedure should be simple with a low recurrence rate, should not require prolonged hospital stay, associated with minimal pain and also decrease the patient's time off-work (16). The limberg reconstruction flap procedure was first described in 1946 and it meets all the criteria to come up as an ideal procedure for this condition when performed with appropriate surgical principles.

This study was done to evaluate the role of rhomboid excision with limberg reconstruction flap procedure in the management of pilonidal sinus disease.

\section{Materials and Methods:-}

Ours was a prospective study conducted in the department of surgery at a rural centre hospital of Kahmir from November 2013 to February 2015. A total number of 25 patients were treated with rhomboid excision with limberg flap reconstruction during this period. Those patients who presented with pilonidal abscess were first treated by simple incision and drainage and later on followed by a definitive procedure. Patients were operated under general or regional anaesthesia. Patients were placed in a prone jack-knife position with the buttocks strapped. After proper asepsis markings were done for both excision area as well as the flap. A rhomboid incision was then made down to the presacral fascia to excise the pilonidal sinus tract. Now the flap was raised by extending the incision laterally . A separate stab incision was used to place a suction drain. After ensuring complete hemostasis the flap was transposed to the excised area and closed in two 2 layers.

Postoperatively the drain was removed after $48-72$ hours whileas the sutures were removed on $12^{\text {th }}-15^{\text {th }}$ postoperative day.

Postoperatively patients were advised to avoid long term sitting and exercise for 2 weeks and local hair removal for a period of 6-8 weeks. The patients were followed in the outpatient department for a period of six months. Parameters like postoperative complications, hospital stay, time off-work and recurrences were recorded.

\section{Results:-}

Our study included a total of 25 patients. In our study 18 (72\%) patients were male and 7(28\%) were female. Age of patients ranged from $16-42$ years with a mean age of 28 years.

Of the 25 patients in our study 15 patients presented with a discharging sinus, 6 patients presented with pain, 2 with abscess and 2 with infection. (Table 1)

Table 1:-Symptoms of patients

\begin{tabular}{|l|l|l|}
\hline SYMPTOMS & NO OF PATIENTS & PERCENTAGE \\
\hline Discharge & 15 & $60 \%$ \\
\hline Pain & 6 & $24 \%$ \\
\hline Infection & 2 & $8 \%$ \\
\hline Abscess & 2 & $8 \%$ \\
\hline
\end{tabular}

In our study the operative time ranged from 50 minutes to 90 minutes. Drain was removed after 48-72 hours and patients were discharged the same day as the removal of drain. Sutures were removed on $12^{\text {th }}-15^{\text {th }}$ postoperative day. (Table 2).

Table 2:-Early post-operative data

\begin{tabular}{|l|l|}
\hline Operative Time & $50-90$ Minutes \\
\hline Hospital Stay & $48-72$ Hours \\
\hline Drain Removal & $48-72$ Hours \\
\hline
\end{tabular}


One patient in our study developed wound site infection postoperatively and was managed conservatively. One patient had seroma, while as one patient had flap necrosis at the tip of the flap. Overall only one patient had a recurrence during the follow-up.(Table 3).

Table 3:-Post-operative Complications

\begin{tabular}{|l|l|l|}
\hline Complication & No of Patients & Percentage \\
\hline Infection & 1 & $4 \%$ \\
\hline Seroma & 1 & $4 \%$ \\
\hline Necrosis & 1 & $4 \%$ \\
\hline Recurrence & 1 & $4 \%$ \\
\hline
\end{tabular}

In our study patients returned to their normal activity i.e the time off-work was $14-22$ days while as time to walk without pain postoperatively ranged from $12-16$ days. (Table 4 )

Table 4:-Clinical Outcomes

\begin{tabular}{|l|l|}
\hline TIME OFF-WORK & $14-22$ DAYS \\
\hline TIME TO WALK WITHOUT PAIN & $12-16$ DAYS \\
\hline
\end{tabular}

\section{Discussion:-}

Pilonidal sinus is a disease entity where management still needs a lot of attention to prevent recurrences. On review of literature, the recurrence rates vary from $20 \%$ to $40 \%$ and sometimes more (17). Treatment varies according to the clinical presentation of the disease. Although many surgical methods have been suggested, an ideal method is still lacking because of high recurrence rates. Recurrent disease causes significant morbidity, particularly affecting the daily routine of the patients. Wide excision of the pilonidal disease followed by natal cleft flattening would be an ideal management for optimal result and reduced recurrence risk. However, a long list of surgical techniques reflects the inability to find an efficient mode of treatment approved by all surgeons. Conventional techniques have problems of high infection and recurrence rate. On the other hand procedures that flatten the intergluteal sulcus and bring the suture line aside midline seem to be superior in terms of postoperative morbidity and recurrence rate [18]. Recurrence for incision and drainage range from $21.4 \%$ to $100 \%$, for excision with open packing $5.5 \%-33 \%$, for marsupialisation about $8 \%$ and for $\mathrm{z}$ - plasty $3.3 \%$ to $11 \%(19,20)$.

A total of 25 patients were operated with a rhomboid excision and limberg reconstruction flap in our study. Recurrence was seen in one patient ( 4\%). Urhan et al (21) operated on 102 patients and reported a recurrence rate of $4.9 \%$ which is comparable to our study.

In our study we had one patient ( $4 \%$ ) with a postoperative flap necrosis at the tip of the flap. Similar results were seen in a study done by El Khadrawy et al( 22).

The time off-work in our study was $14-22$ days . Similar results were reported by Abu Galala et al (23).

From time to time various other studies have been conducted and the results of our study are comparable to these studies as is depicted in table 5.

Table 5:-

\begin{tabular}{|l|l|l|l|l|}
\hline Study & No of Patients & Hospital Stay(days) & $\begin{array}{l}\text { Complications } \\
\text { (Percentage) }\end{array}$ & $\begin{array}{r}\text { Recurrence } \\
\text { (Percentage) }\end{array}$ \\
\hline Akin et al(4) & 411 & 3.2 & 15.75 & 2.91 \\
\hline Urhan et al (12) & 102 & 3.7 & 7 & 4.9 \\
\hline Mentes et al(24) & 238 & $2-3$ & 2 & 1.26 \\
\hline Aslam et al (3) & 110 & 3.0 & 5 & 1 \\
\hline El Khadrawy et al (13) & 40 & $5-11$ & 40 & 10 \\
\hline Current study & 25 & $2-3$ & 16 & 4 \\
\hline
\end{tabular}




\section{Conclusion:-}

Rhomboid excision with limberg reconstruction flap procedure is a very effective procedure for pilonidal sinus disease. The procedure is easy to learn and perform. It is associated with a low recurrence, a shorter hospital stay, less complication rates and faster healing. We recommend this procedure for the treatment of pilonidal sinus disease.

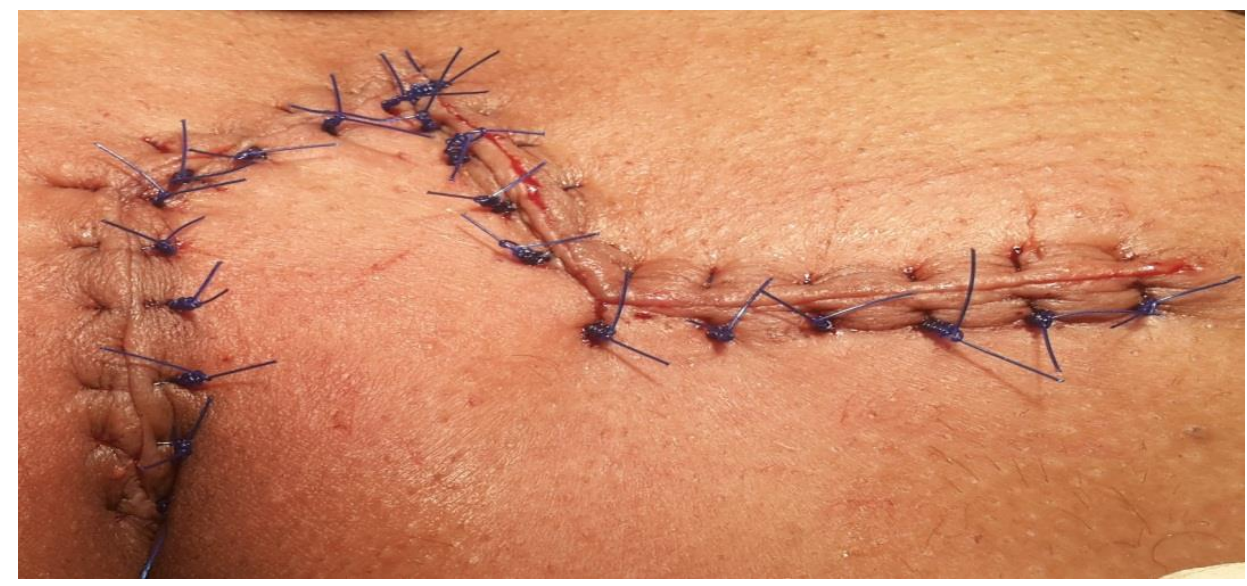

Figure1:-Post-operative wound after closure

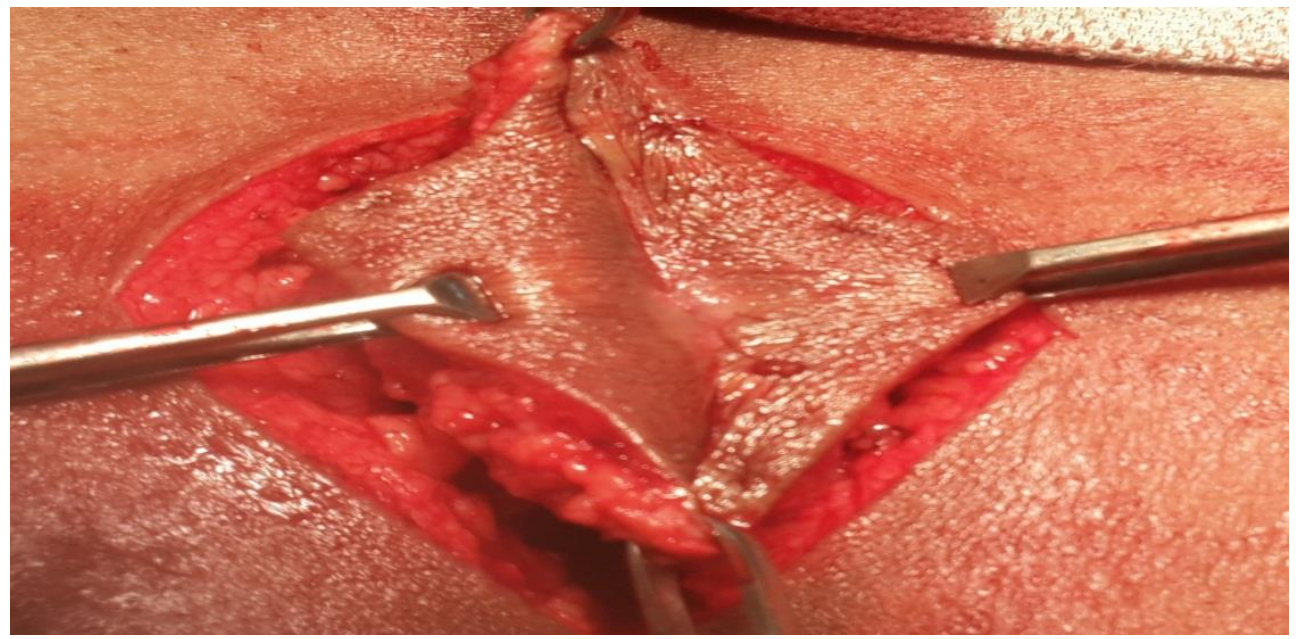

Figure 2:-Figure showing rhomboid excision of pilonidal sinus

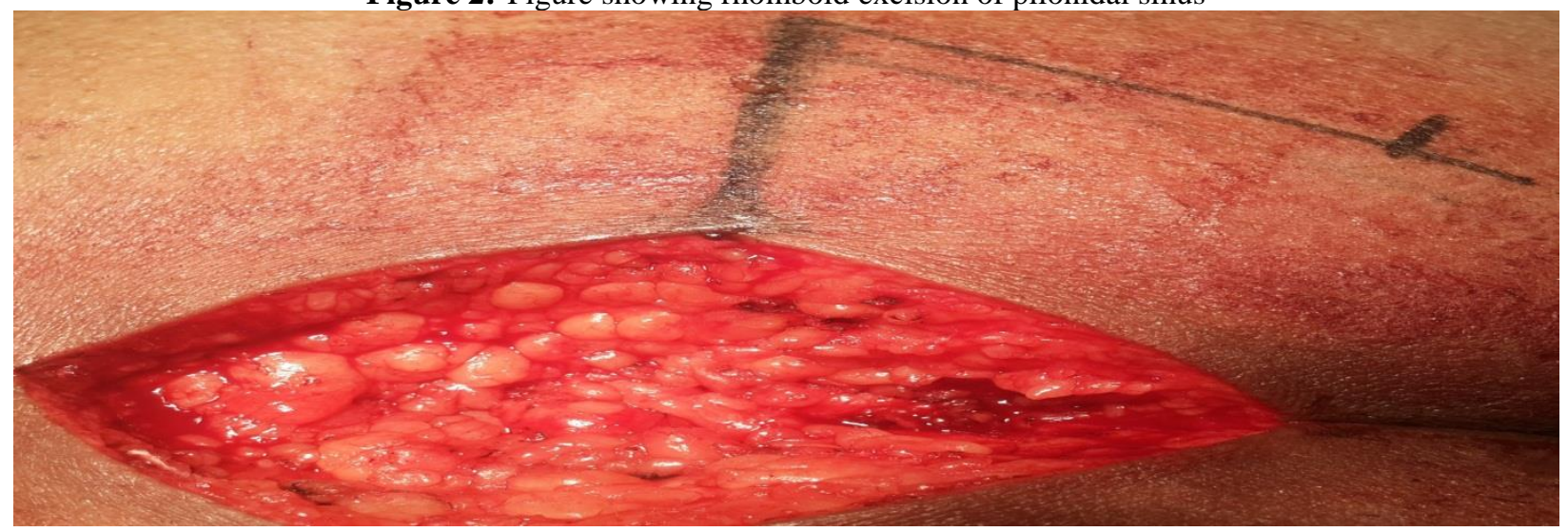

Figure 3:-Showing Rhomboid excision with flap marking 


\section{References:-}

1. Sondenna k, Anderson E, Nesvik I, Soreide JA .Patient characteristics and symptoms in chronic pilonidal sinus disease . Int J Colorectal Dis 1995 Feb ; 10(1):39-42.

2. Z Matar. Pilonidal Sinus Disease: A 5-year study. The Internet Journal of surgery.2006 volume 13 Number 2.

3. Aslam MN, Shoaib S , Choudhry AM .Use of limberg flap for pilonidal sinus - a viable option. J Ayub Med Coll Abbottabad 2009 oct - dec ; 21(4):31 - 3.

4. Akin M , Gokbayir H, Kilic K, Topgul K, Ozdemir E, Farahkose Z . Rhomboid excision and limberg flap for managing pilonidal sinus : long term results in 411 patients . Colorectal Dis 2008 Nov ; 10(9) : $945-8$.

5. Armstrong JH, Barcia PJ: Pilonidal sinus disease. The conservative approach. Arch Surg, 1994; 129(9): 914-17; discussion $917-19$

6. Schneider IH, Thaler K, Kockerling F: Treatment of pilonidal sinuses by phenol injections. Int J Colorectal Dis, 1994; 9(4): 200-2

7. Kepenekci I, Demirkan A, Celasin H, Gecim IE: Unroofing and curettage for the treatment of acute and chronic pilonidal disease. World J Surg, 2010; 34(1): 153-57

8. da Silva JH: Pilonidal cyst: cause and treatment. Dis Colon Rectum, 2000; 43(8): 1146-56

9. Berkem H, Topaloglu S, Ozel H et al: V-Y advancement flap closures for complicated pilonidal sinus disease. Int J Colorectal Dis, 2005; 20(4): 343-48

10. Bascom JU: Repeat pilonidal operations. Am J Surg, 1987; 154(1): 118-22

11. Arumugam PJ, Chandrasekaran TV, Morgan AR et al: The rhomboid flap for pilonidal disease. Colorectal Dis, 2003; 5(3): 218-21

12. Mentes BB, Leventoglu S, Cihan A et al: Modified Limberg transposition flap for sacrococcygeal pilonidal sinus. Surg Today, 2004; 34(5): 419-23

13.. Karydakis GE: New approach to the problem of pilonidal sinus. Lancet, 1973; 2(7843): 1414-15

14. Bessa SS: Results of the lateral advancing flap operation (modified Karydakis procedure) for the management of pilonidal sinus disease. Dis Colon Rectum, 2007; 50(11): 1935-40

15. Stroosma OC: Gluteal fasciaplasty as a method of primary closure in the treatment of pilonidal sinus. Arch Chir Neerl, 1978; 30(1): 61-64

16. Solla JA , Rothenberger DA . Chronic pilonidal disease . An assessment of 150 cases . Dis Colon Rectum 1990 sep ; 33(9):758 - 61 .

17. Ringelheim R, Silverberg MA, Villanueva NJJ . Pilonidal cyst and sinuses : emedicine article. www.emedicine.com/emrg/topic $771 \mathrm{htm}$.

18. Cihan A, Mentes BB, Tatlicioglu E, Ozmen S, Leventoglu S, Ucan BH. Modified Limberg flap reconstruction compares favourably with primary repair for pilonidal sinus surgery. Aust N Z J Surg. 2004;74:238.

19. Jensen SL , Harling H . Prognosis after simple incision and drainage for a first-episode acute pilonidal abscess . Br J Surg 1988 jan ; 75(1) : $60-1$.

20. Sabet AM , El Shaer WMH , El Amary MK . Definitive treatment of recurrent pilonidal sinus disease using rhomboid excision and limberg flap . Egypt J Surg 2004 oct ; 23(4) : $324-7$.

21.Urhan MK, Kucukel F, Topgul K, Ozer I, Sari S . Rhomboid excision and limberg flap for managing pilonidal sinus : result of 102 cases . Dis Colon Rectum $2002 ; 45(5): 656$ - 9.

22.El Khadrawy OH . The rhomboid flap for recurrent pilonidal disease. Tanta Med Sci J 2006 ; 1(4) : $175-81$.

23. Abu Galala KH, Salam IM , Abu Samaan KR, El Ashaal YI, Chandran VP, Sabastian M . Treatment of pilonidal sinus by primary closure with a transposed rhomboid flap compared with deep suturing : a prospective randomised clinical trial . Eur J Surg 1999 may : 165(5) : $468-72$.

24. Mentes BB , Leventoglu S, Cehan A, Tatlicioglu E, Akin M, Oguz M . Modified limberg transposition flap for sacrococcygeal pilonidal sinus. Surg today 2004 may ; 34(5) : $419-23$. 